\title{
Funktionale Gesichtspunkte des Theaters und des Amphitheaters im architektonischen, sozialen und politischen Kontext
}

\section{Thomas Hufschmid}

\author{
(2) OpenEdition \\ Journals \\ Édition électronique \\ URL : https://journals.openedition.org/edl/119 \\ DOI : $10.4000 /$ edl. 119 \\ ISSN : 2296-5084 \\ Éditeur \\ Université de Lausanne \\ Édition imprimée \\ Date de publication : 15 mai 2011 \\ Pagination : 263-292 \\ ISBN : 978-2-940331-25-3 \\ ISSN : 0014-2026 \\ Référence électronique \\ Thomas Hufschmid, „Funktionale Gesichtspunkte des Theaters und des Amphitheaters im \\ architektonischen, sozialen und politischen Kontext", Études de lettres [Online], 1-2 | 2011, Online \\ erschienen am: 15 Mai 2014, abgerufen am 21 September 2021. URL: http://journals.openedition.org/ \\ edl/119; DOI: https://doi.org/10.4000/edl.119
}




\title{
FUNKTIONALE GESICHTSPUNKTE DES THEATERS UND DES AMPHITHEATERS IM ARCHITEKTONISCHEN, SOZIALEN UND POLITISCHEN KONTEXT
}

In die Errichtung der römischen Theaterbauten und die Durchführung der darin stattfindenden Spiele wurden oft gewaltige finanzielle Mittel investiert. Dies zeigt, dass die Veranstaltungen in den Theatern und Amphitheatern nicht allein als Unterhaltung der Volksmassen dienten, sondern auch Mittel der politischen Interaktion waren und eine wichtige Grundlage der gesellschaftlichen, politischen und religiösen Propaganda darstellten. Mittels einer potenten Bildsprache wurde soziale Ordnung visualisiert, kulturelle Zusammengehörigkeit demonstriert und imperiale Macht legitimiert. Die rituelle Zelebrierung des Sieges unterstrich zudem den hegemonialen Machtanspruch Roms. Als Rahmen für diese Inszenierungen dienten die Theaterbauten mit ihrer funktional durchdachten Architektur und ihren technischen Einrichtungen.

\begin{abstract}
Ainsi, la protection symbolique de la société atteint aux munera son comble, quand les spectateurs rangés en bon ordre [...] assistent à l'élimination, à l'écrasement et à la soumission de tous les ennemis réels ou potentiels de l'ordre [...]. Comment mieux aussi diffuser dans les masses des leçons de peur dominée, de discipline, de soumission, de courage et de force virile, dont ces êtres diminués [...] montrent l'exemple ${ }^{1}$.
\end{abstract}

In diesen 1984 von Monique Clavel-Lévêque verfassten Zeilen schlägt sich bereits ein grosser Teil der Bedeutung nieder, welche den Spielen in den römischen Arenen und Theatern zukam. „Die römischen ,Spiele“ waren kein Spiel " betont der Kulturhistoriker Egon Flaig in einem 2003 erschienenen Aufsatz, der sich mit der Bedeutung der Spiele als

I. M. Clavel-Lévêque, L'empire en jeux, S. 71. 
Instrument zur politischen Integration auseinandersetzt ${ }^{2}$. Und gerade weil diese Veranstaltungen in den Arenen der Amphitheater, auf den Bühnen der Theater und den Rennstrecken der Circi viel mehr als blosse Unterhaltung der Volksmassen waren, wurden für deren Durchführung oft immense Geldsummen investiert, welche den Veranstalter (editor) zuweilen an den Rand des Ruins bringen konnten ${ }^{3}$. Riesige Summen verschlangen aber auch die Errichtung und der Betrieb der Veranstaltungsgebäude selbst; Bauwerke, die oft mit raffinierten technischen Einrichtungen versehen waren, um den komplexen szenographischen Abläufen der Spiele gerecht zu werden und den berühmten deus ex machina aus dem Boden herauf- oder vom Himmel herabsteigen zu lassen. Zudem galt es, die Erschliessung dieser Bauten so zu gestalten, dass das Auf- und Abtreten der Akteure optimal gewährleistet war, aber auch, dass die Zuschauer möglichst rasch zu ihren Sitzplätzen gelangen konnten.

Die genannten Beispiele zeigen, dass die antiken Theaterbauten einer Vielzahl von funktionalen Anforderungen genügen mussten, die sich nicht allein auf technische Einrichtungen, sondern auch auf gesellschaftliche und politische Aspekte erstreckten.

\section{Technische Funktionalität}

Ein optimales Funktionieren der Theaterbauten und der darin durchgeführten Veranstaltungen hing in erster Linie von der technischen Ausstattung der Bauwerke ab. Verschiedene Räumlichkeiten und bauliche Installationen waren notwendig, um die Qualität der Inszenierungen und einen gewissen Komfort für die Zuschauer zu gewährleisten.

\subsection{Zugänge und Erschliessungssysteme}

Ein wesentliches Element eines jeden Theaterbaus bildete die Organisation der Zugangs- und Treppensysteme, welche für die Verteilung des Publikums auf die Sitzplätze und ein rasches Entleeren des Theaters nach Beendigung der Veranstaltungen verantwortlich

2. E. Flaig, Ritualisierte Politik, S. 232.

3. K.-W. Weeber, Panem et circenses, S. $46 \mathrm{ff}$. 


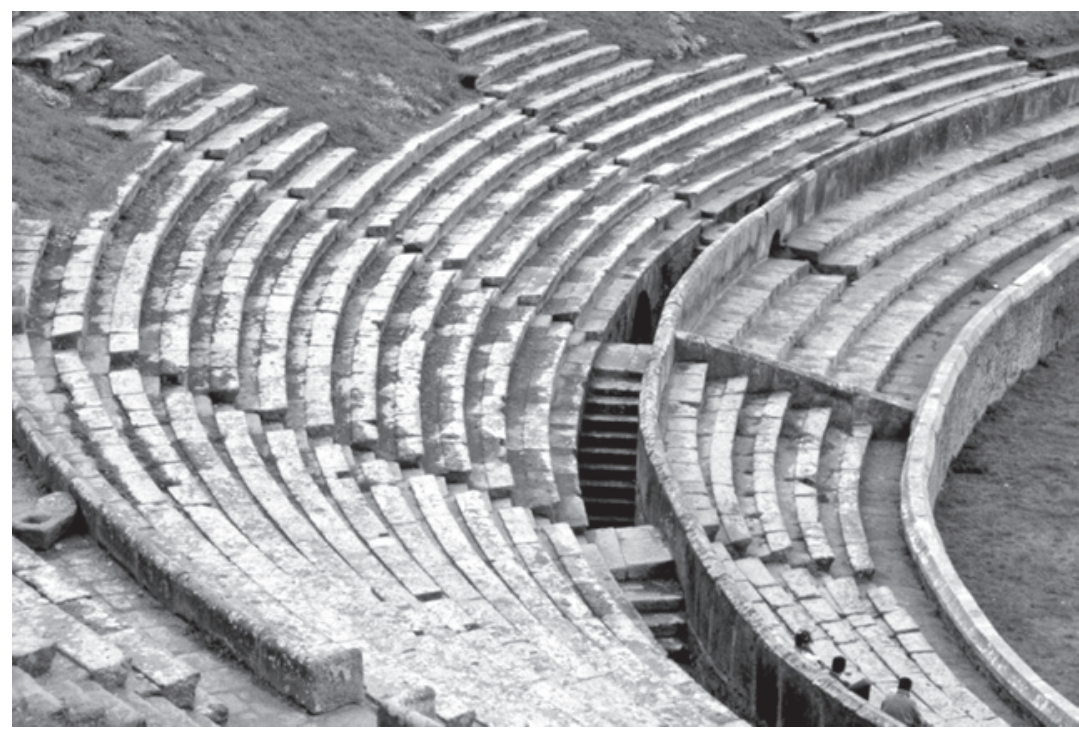

Abb. 1 - Amphitheater von Pompeji, Ausschnitt aus der Sitzstufenzone mit cunei und scalaria.

waren. Als prägende Elemente finden sich daher zumeist überwölbte Zugangskorridore (vomitoria) welche von der Peripherie her zu den Sitzplatzbereichen, der sogenannten cavea, führten ${ }^{4}$. Die weitere Verteilung des Publikums auf dessen Sitzplätze im Oval oder Halbrund der Sitzstufenzone erfolgte über radial angelegte Treppenläufe (scalaria) innerhalb der cavea (Abb. 1). Diese Treppen gewährleisteten nicht nur eine effiziente Erschliessung der einzelnen Sitzplätze, sondern teilten die cavea gleichzeitig auch in keilförmige Zonen (cunei) auf, welche durchnummeriert waren und so ein massgebliches Element zur Organisation der Sitzplatzzone darstellten ${ }^{5}$. Bei den grossen, mit Bogenfassaden versehenen Bauten in Italien waren zudem die einzelnen Arkaden an der

4. Zu den vomitoria, der cavea und den einzelnen Bereichen der Sitzplatzzone, vgl. Th. Hufschmid, Amphitheatrum in Provincia et Italia, S. 27 ff., 34, 48 f. und 55. Zur cavea und deren Funktion, ausserdem auch J.-C. Golvin, L'amphithéâtre romain, S. $341 \mathrm{ff}$.

5. Th. Hufschmid, Amphitheatrum in Provincia et Italia, S. 32 ff.; J.-C. Golvin, L'amphithéâtre romain, S. $346 \mathrm{ff}$. Ein konkretes Beispiel für eine derartige Nummerierung der cunei findet sich im Amphitheater von Pozzuoli, wo an den Brüstungsplatten der Vomitoriumsmündungen die Nummer des jeweiligen cuneus eingemeisselt war. Vgl. A. Maiuri, Studi e ricerche sull'Anfiteatro Flavio Puteolano, S. $56 \mathrm{ff}$. 
Peripherie mit Nummern versehen, damit die Zuschauer möglichst rasch den in die Nähe ihres Sitzplatzes führenden Eingang finden konnten ${ }^{6}$.

Nebst der guten Zugänglichkeit zur Sitzplatzzone kam aber auch der Erschliessung der arenae der Amphitheater respektive der orchestrae der Bühnentheater eine wichtige Bedeutung zu. Diese Zonen waren in der Regel über zwei einander gegenüberliegende breite Eingänge, die aditus maximi (beim Bühnentheater oft auch als parodoi bezeichnet), zugänglich, welche bei den Bühnentheatern zuweilen, bei den Amphitheatern in den meisten Fällen befahrbar waren. Bei den Bühnentheatern dienten diese breiten Eingänge der Erschliessung der Prohedrie und dem Chor und weiteren in Gruppen auftretenden Akteuren als Zugang zur orche$s t r a^{7}$. Bei den Amphitheatern hingegen wurden durch die grossen Tore dieser Eingänge Kulissen und Akteure in die arena gefahren und bei Jagdinszenierungen Tierrudel durch diese Gänge auf den Kampfplatz getrieben. Bei Gladiatorenkämpfen zu Pferd ritten die Kontrahenten (equites) durch die breiten Zugänge und trafen sich im Zentrum der arena zum Zweikampf ${ }^{8}$. Die in die arena mündenden Tore dieser Zugänge besassen zudem eine hochgradig symbolische Bedeutung und trugen die Bezeichnung porta sanavivaria („Tor des Lebens“) und porta libitinensis („Tor des Todes“). Durch das eine Tor verliessen die siegreichen Gladiatoren und Tierkämpfer den Kampfplatz, durch das andere wurden die Kadaver der in der arena getöteten Menschen und Tiere hinausgetragen ${ }^{9}$.

\section{2. „Serviceräume“ (carceres) und Bedienungsgänge}

Wesentliche bauliche Elemente, die zum effizienten Funktionieren der Amphitheater beitrugen, waren die „Serviceräume“, welche über

6. Beim Amphitheatrum Flavium in Rom waren die im Erdgeschoss liegenden Eingangsarkaden der Umfassungsmauer mit den Zahlen von I bis LXXVI durchnummeriert und erlaubten so eine effiziente Erschliessung des Bauwerks. Vgl. A. Gabucci (ed.), Il Colosseo, S. 135. Eine ähnliche Nummerierung ist partiell auch beim Amphitheater von Verona erhalten geblieben. Vgl. K. E. Welch, The Roman amphitheatre, S. $186 \mathrm{ff}$. mit Taf. 10.

7. Vgl. auch F. Sear, Roman theatres, S. 68; P. Cianco Rossetto, G. Pisani Sartorio, Teatri greci e romani, S. $136 \mathrm{f}$.

8. Isidorus, Etymologiae 18.53; M. Junkelmann, Das Spiel mit dem Tod, S. $123 \mathrm{f}$.

9. Th. Hufschmid, Amphitheatrum in Provincia et Italia, S. $42 \mathrm{f}$. 


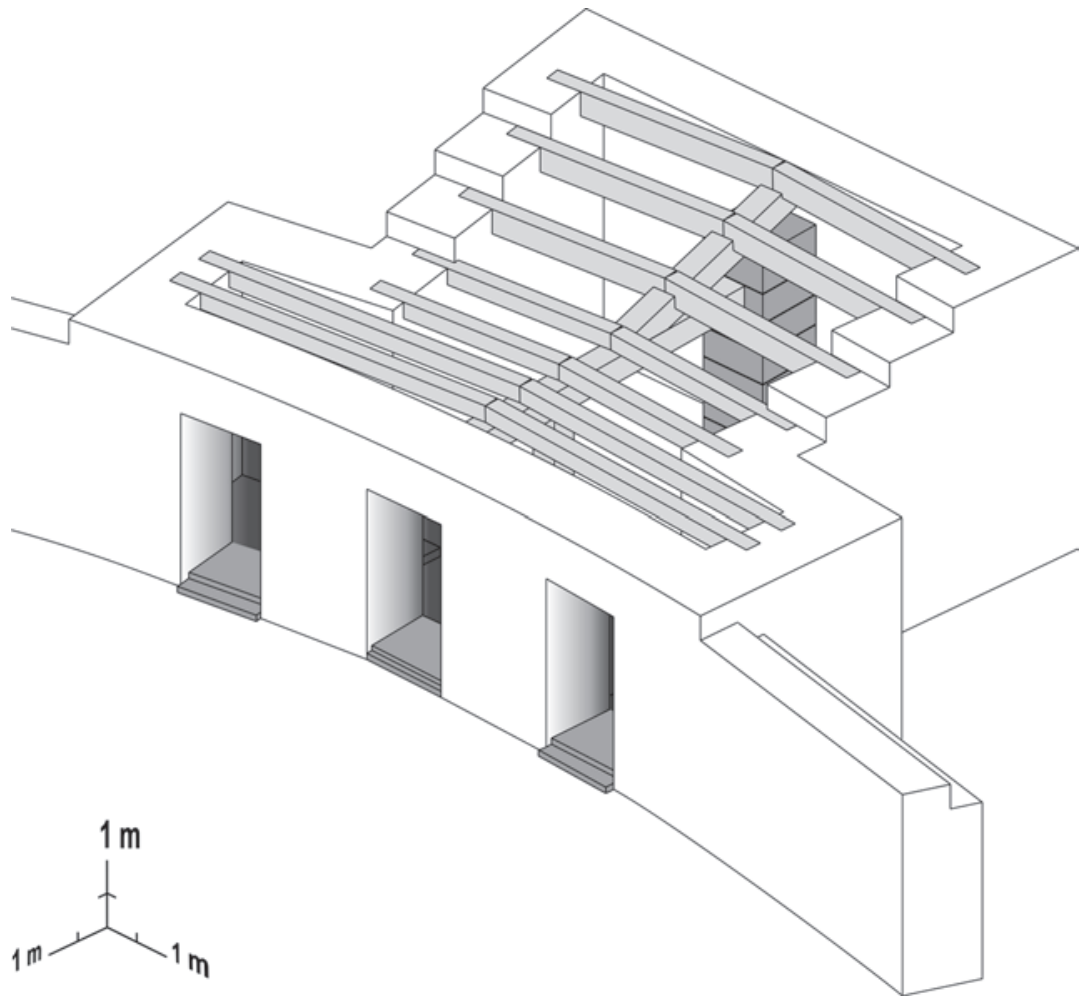

Abb. 2 - Amphitheater von Augst-Neun Türme, Ostcarcer mit drei nebeneinander liegenden portae posticae.

enge Pforten (portae posticae) direkt mit der arena in Verbindung standen (Abb. 2). In der Fachliteratur werden diese Räume oft als carceres bezeichnet und ausschliesslich mit der Haltung von wilden Tieren in Verbindung gebracht ${ }^{10}$. Diese Räume wiesen aber ausgeprägte multifunktionale Aspekte auf und wurden je nach Art der Veranstaltung unterschiedlich genutzt. So dienten sie bei den munera den Gladiatoren und ihren Helfern (ministri) als Aufenthaltsort vor dem Kampf und als Ausgangspunkt für den inszenierten Auftritt in der arena. Wurden dagegen venationes geboten, so konnten einerseits aus in den Räumen postierten Käfigen wilde Tiere durch die portae posticae auf den Kampfplatz entlassen werden, andererseits von Raubtieren verfolgte Tierkämpfer in

Io. Vgl. etwa J.-C. Golvin, L'amphithéâtre romain, S. 328. 


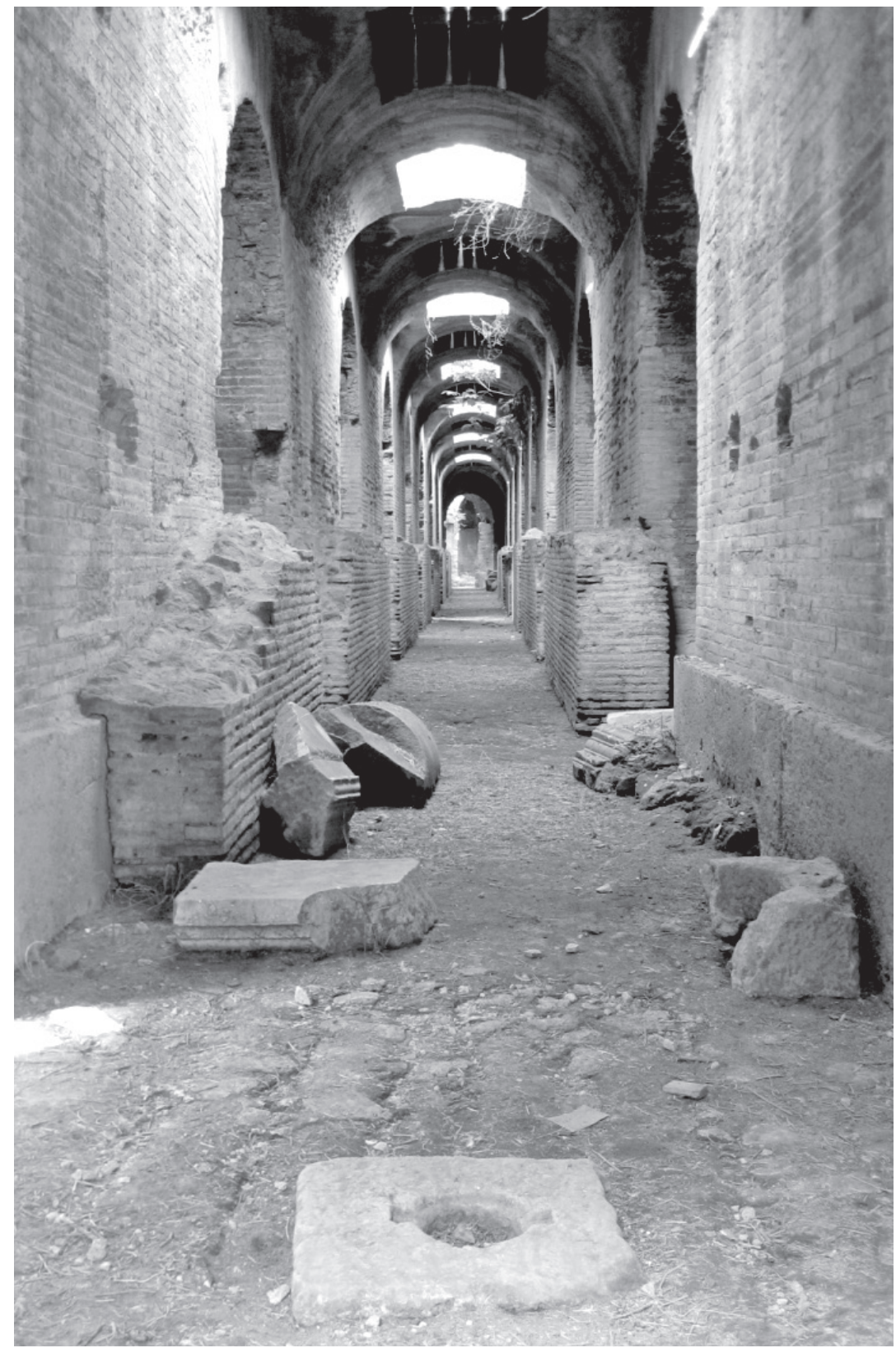

Abb. 3 - Amphitheater von Capua, Untergeschoss mit Austrittsluken für die Lifte (pegmata). Im Vordergrund ein Steinblock mit runder Aussparung zum Einsetzen einer Haspelwinde. 
diesen Räumen Schutz suchen ${ }^{11}$. All diese unterschiedlichen Arten der Verwendung sind auf kaiserzeitlichen Steinreliefs und Mosaiken sowie spätantiken Konsulardiptychen dargestellt ${ }^{12}$.

Nebst den „Serviceräumen “ bildeten Arenaumgänge, welche hinter der die arena begrenzenden Podiumsmauer verliefen, ein wesentliches Element zur Bedienung des Kampfplatzes. Diese oft sehr engen Gänge waren über verschiedene portae posticae mit der Kampfzone verbunden und erlaubten so eine hohe, in einem für die Zuschauer versteckten Bereich stattfindende Mobilität rund um die $\operatorname{arena}^{13}$. In der Regel verliefen diese Umgänge beidseits der arena, bei einigen wenigen Bauten findet sich der Gang aber auch nur auf einer Seite ${ }^{14}$.

\subsection{Untergeschosse und Liftsysteme der grossen Amphitheater}

Technisch beeindruckend waren zweifellos die Lift- und Hebesysteme (pegmata), mittels derer bei den grossen Amphitheatern des mediterranen Raums Bühnendekore und in Käfigen postierte Tiere von oft zweistöckigen Untergeschossen zum Kampfplatz gefahren werden konnten (Abb. 3). Antike Quellen berichten davon, wie der sich unversehens öffnende Boden eine in der arena aufgebaute Landschaft verschluckt ${ }^{15}$ und wie Tiere durch Luken im Boden auf den Kampfplatz gehievt werden ${ }^{16}$. Die arenae des Kolosseums in Rom und der grossen Amphitheater von Capua und Pozzuoli waren geradezu übersät mit solchen Liftschächten

II. Th. Hufschmid, Amphitheatrum in Provincia et Italia, S. $202 \mathrm{ff}$. Die Multifunktionalität dieser Räume wird zuweilen auch dadurch unterstrichen, dass sie zwei oder sogar drei Verbindungstüren mit der arena aufwiesen, so dass mehrere Akteure (Menschen und Tiere) den Kampfplatz gleichzeitig betreten oder verlassen konnten.

I2. Vgl. beispielsweise A. Gabucci (ed.), Il Colosseo, S. 49, 70 und 94.

I3. Th. Hufschmid, Amphitheatrum in Provincia et Italia, S. $210 \mathrm{ff}$. und $526 \mathrm{mit}$ Tab. 4; J.-C. Golvin, L'amphithéâtre romain, S. $326 \mathrm{ff}$.

I4. So etwa beim Amphitheater von Avenches, wo der vermutlich über vier portae posticae mit der arena verbundene Gang lediglich auf der Südseite existierte (Ph. Bridel, L'amphithéâtre d'Avenches, S. $46 \mathrm{ff} ., 210 \mathrm{f}$. und Beilage 11; vgl. auch den Beitrag von $\mathrm{Ph}$. Bridel in diesem Band).

I5. Apuleius, Metamorphosen 10.34.2: ... montem illum ligneum terrae uorago decepit...

16. Calpurnius, Eclogae $7.69 \mathrm{ff} .:$ Ah! trepidi quotiens sola discedentis harenae uidimus in partes, ruptaque uoragine terrae emersisse feras! 


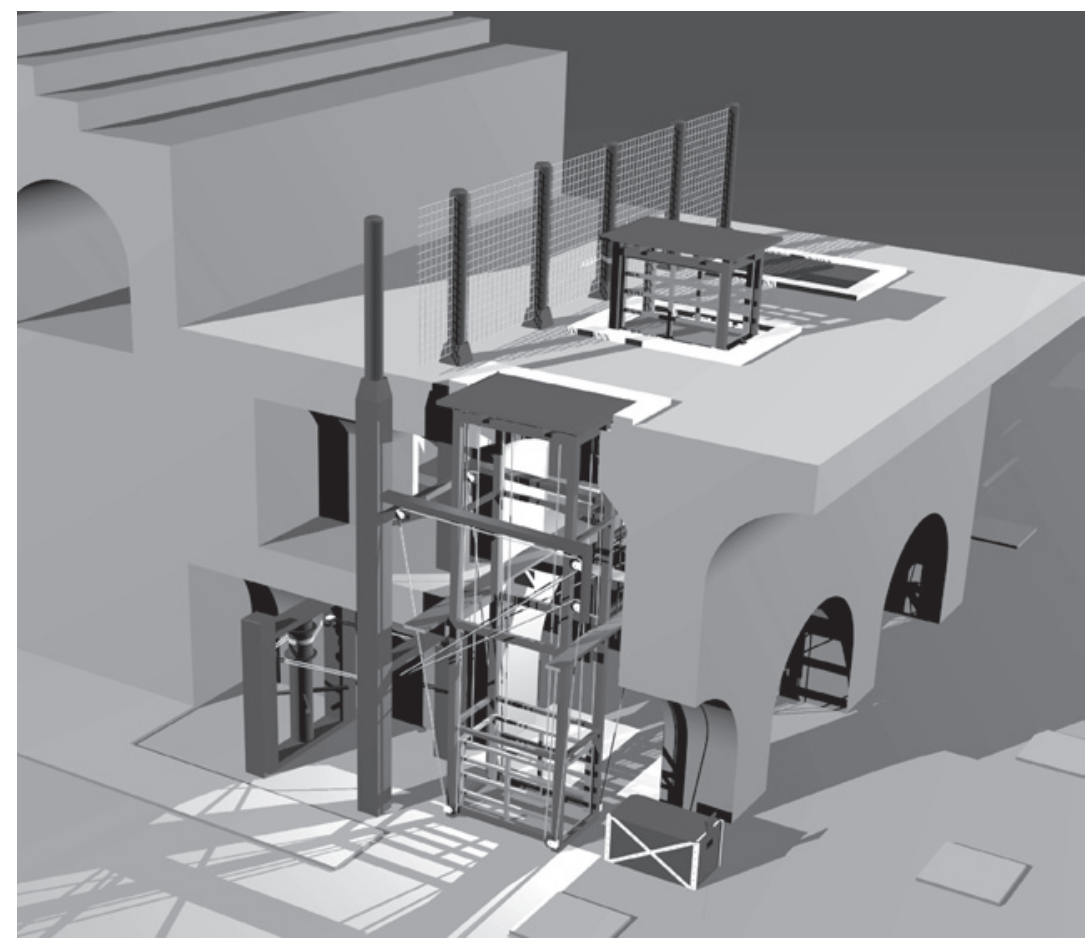

Abb. 4 - Amphitheater von Pozzuoli, Isometrie mit Schnitt durch das Untergeschoss. Im Vordergrund eine geschlossene Austrittsluke mit zugehöriger Liftkonstruktion (pegma) und Seilwinde; im Zentrum eine geöffnete Luke mit hochgefahrener Holzabdeckung. Ohne Massstab.

und Bühnengräben, die bis zu einem Viertel der Arenafläche einnehmen konnten (vgl. Abb. 5). Diese Luken wurden aber nicht alle gleichzeitig verwendet, sondern kamen „choreographiert “ im Verlauf einer Veranstaltung, zumeist wohl bei venationes, zum Einsatz. Die technische Ausführung dieser Lifteinrichtungen konnte je nach Bauweise und Zeitepoche leicht unterschiedlich sein; so scheinen die Systeme bis in die flavische Zeit hinein ausschliesslich als „Einzelstationen “ konzipiert gewesen zu sein, so dass jeder Bodenluke ein unabhängiger Lift mit eigener Seilwinde zur Verfügung stand (Abb. 4) ${ }^{17}$. Erst um die Mitte des 2. Jh. n. Chr. wurden Einrichtungen entwickelt, bei denen

I7. H.-J. Beste, „I sotterranei del Colosseo “, S. 288 ff. mit Abb. 14f.; Th. Hufschmid, Amphitheatrum in Provincia et Italia, S. 228 ff. mit Abb. $265 \mathrm{ff}$. 

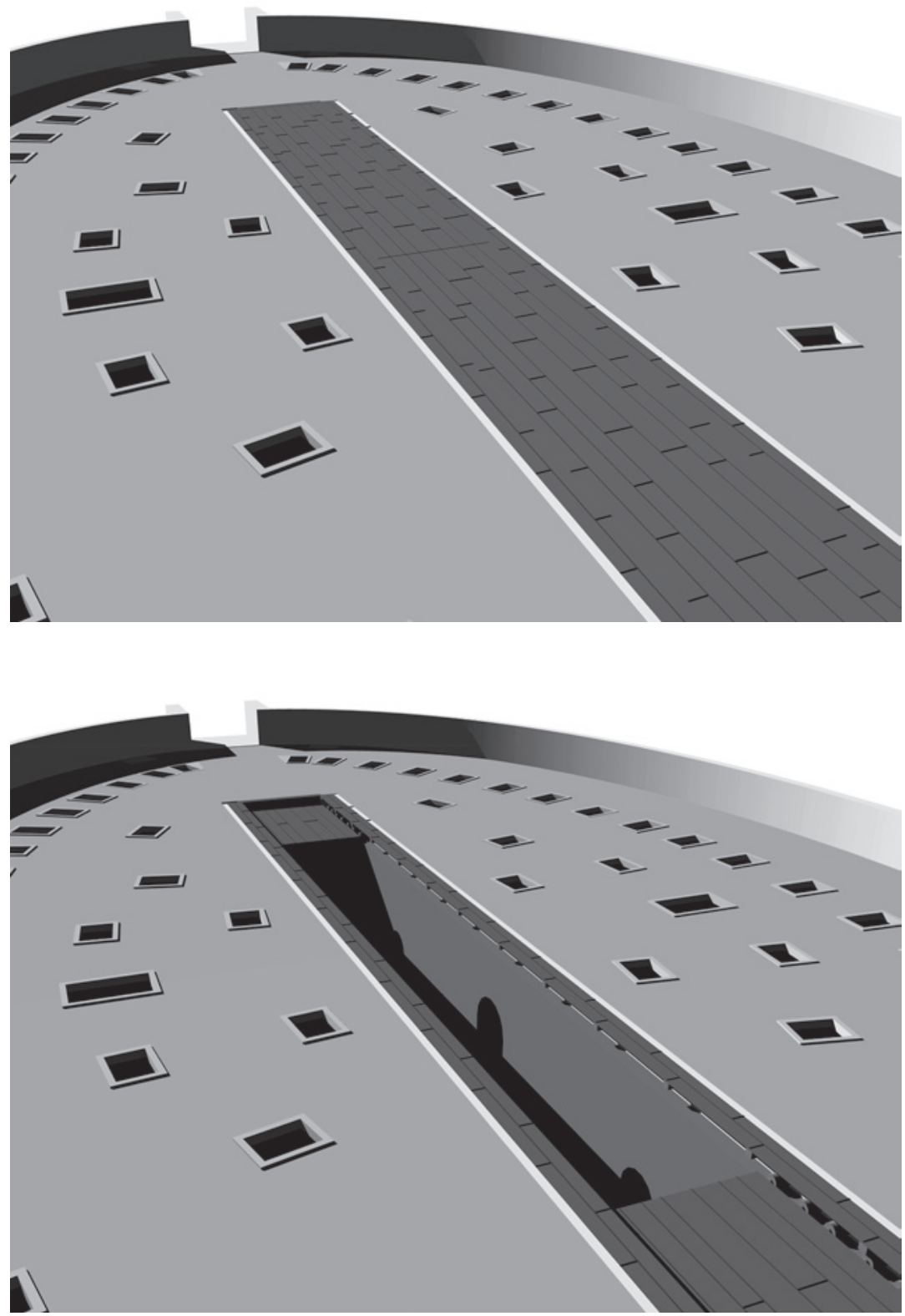

Abb. 5 - Amphitheater von Pozzuoli, Arenafläche mit Austrittsluken und Längsgraben für den Bühnendekor; oben der Graben in geschlossenem Zustand, unten mit zurückgeschobener Holzabdeckung. Ohne Massstab. 
auch mehrere Lifte (zum Teil wohl bis zehn Stück) gemeinsam über eine einzige Winde manövriert werden konnten (vgl. Abb. 3) ${ }^{18}$. Das Öffnen der Schächte geschah dabei nicht, wie oft in der Literatur zu lesen, über an Scharnieren befestigte Klappen, sondern durch Anheben der Holzabdeckung beim Hochfahren des Lifts (Abb. 4) ${ }^{19}$.

Ebenfalls unterschiedliche Hebe- und Abdecksysteme existierten für die im Zentrum der arenae, auf der Längsachse liegenden Bühnengräben, über welche der Landschaftsdekor für Jagdinszenierungen auf den Sandplatz gebracht wurde. Für das Kolosseum in Rom lassen Abarbeitungen an den Seitenwänden der Gräben ein System von Plattformen vermuten, welche über diagonal verlaufende Führungsschienen in die arena geschoben werden konnten ${ }^{20}$. Anders funktionierte die hierfür installierte technische Einrichtung beim Amphitheater von Pozzuoli; wie die baulichen Überreste zeigen, liess sich hier die hölzerne Grabeneindeckung vermutlich auf Rollen auseinanderschieben (Abb. 5), während die Plattformen mit dem Landschaftsdekor vertikal auf die Höhe des Arenaniveaus gezogen oder geschoben wurden ${ }^{21}$.

\subsection{Tierpforten und Servicegänge zum Transport von Tieren in den Amphitheatern}

Bei weitem nicht alle Amphitheater waren mit Untergeschossen und Liftsystemen ausgerüstet, deshalb brauchte es auch noch andere Einrichtungen, um wilde oder gefährliche Tiere in die arena zu bringen. Bei den meisten Amphitheatern finden sich daher spezielle Räume,

I8. H.-J. Beste, „I sotterranei del Colosseo “, S. 294 ff. mit Abb. 20; Th. Hufschmid, Amphitheatrum in Provincia et Italia, S. 228 mit Abb. 261.

19. Th. Hufschmid, Amphitheatrum in Provincia et Italia, S. 230 mit Abb. 265; vgl. ausserdem auch die Aussage Senecas (Epistulae morales ad Lucium 88.22) : machinatores, qui pegmata per se exsurgentia excogitant et tabulata in... sublime crescentia.

20. H.-J. Beste, „I sotterranei del Colosseo “, S. $292 \mathrm{ff}$. mit Abb. 17 f. Mit grösster Wahrscheinlichkeit hat ein System von doppelt vorhandenen Plattformen existiert, von denen die einen als Grabenabdeckung dienten, während die anderen mit fertig montiertem Landschaftsdekor im Untergeschoss in Warteposition waren. Um den Dekor in die arena zu bringen, wurden die Plattformen der Grabenabdeckung unter den nach oben gleitenden Dekorplattformen hindurch in den Graben hinabgelassen. Vgl. Th. Hufschmid, Amphitheatrum in Provincia et Italia, S. 224 mit Abb. 254.

2I. Th. Hufschmid, Amphitheatrum in Provincia et Italia, S. 225 mit Abb. 255-258. 


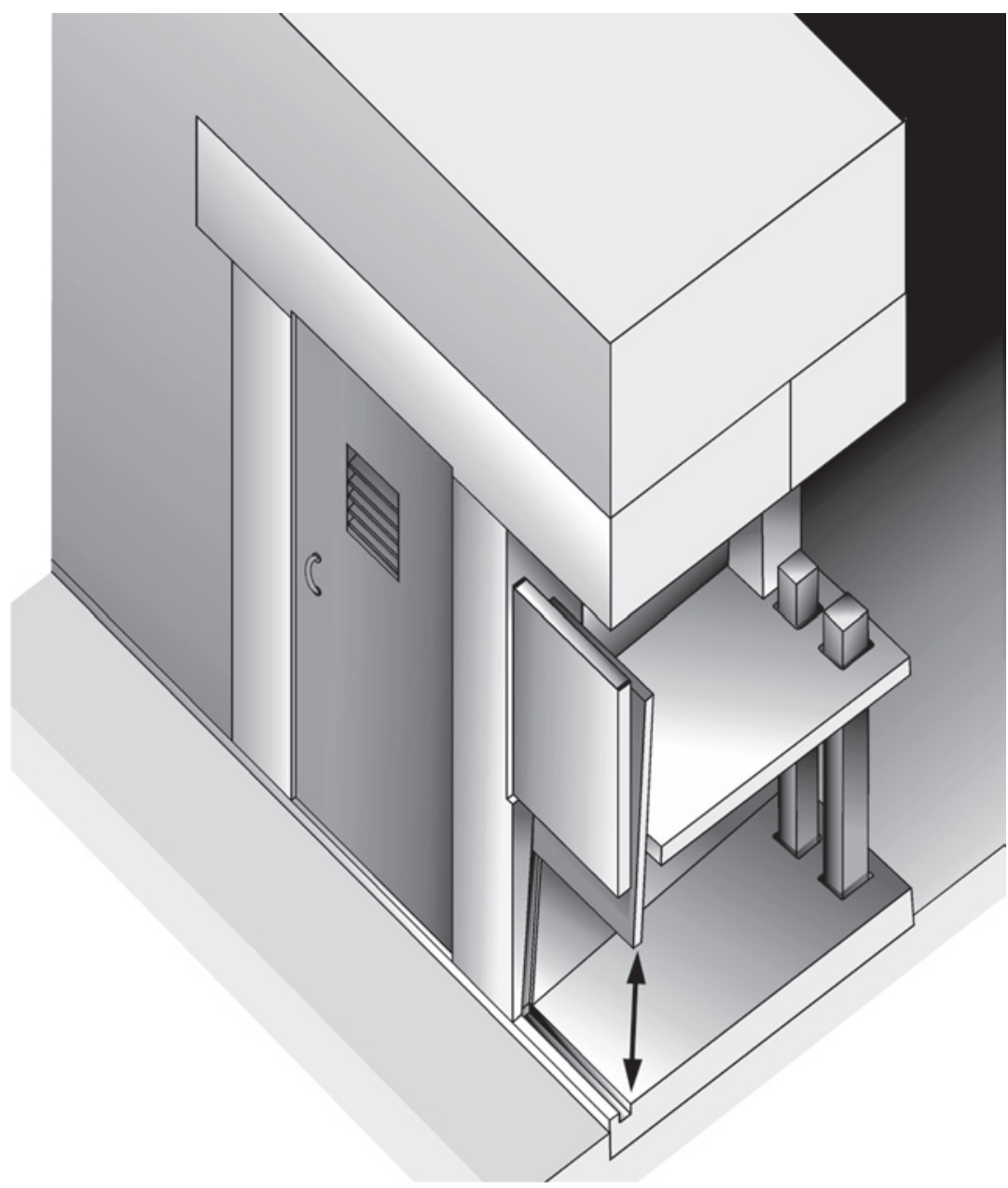

Abb. 6 - Amphitheater von Maktar, porta postica mit angegliedertem Tierkäfig. Die Käfigbox besass zur arena hin eine vertikal verlaufende Schiebetür, während die zum Arenaumgang orientierte Seite mit zwei vertikal eingeschobenen Balken verschlossen wurde. Ohne Massstab.

die über portae posticae mit dem Kampfplatz verbunden waren und das überraschende Entlassen von Tieren in die arena ermöglichten. Bei einigen Bauten wurden die Pforten dieser Räume technisch und in ihren Dimensionen speziell an diesen Gebrauch angepasst und zur sicheren Bedienung mit vertikal gleitenden Schiebetüren versehen. Solche Einrichtungen, zumeist mit einer neben der Schiebetür liegenden 


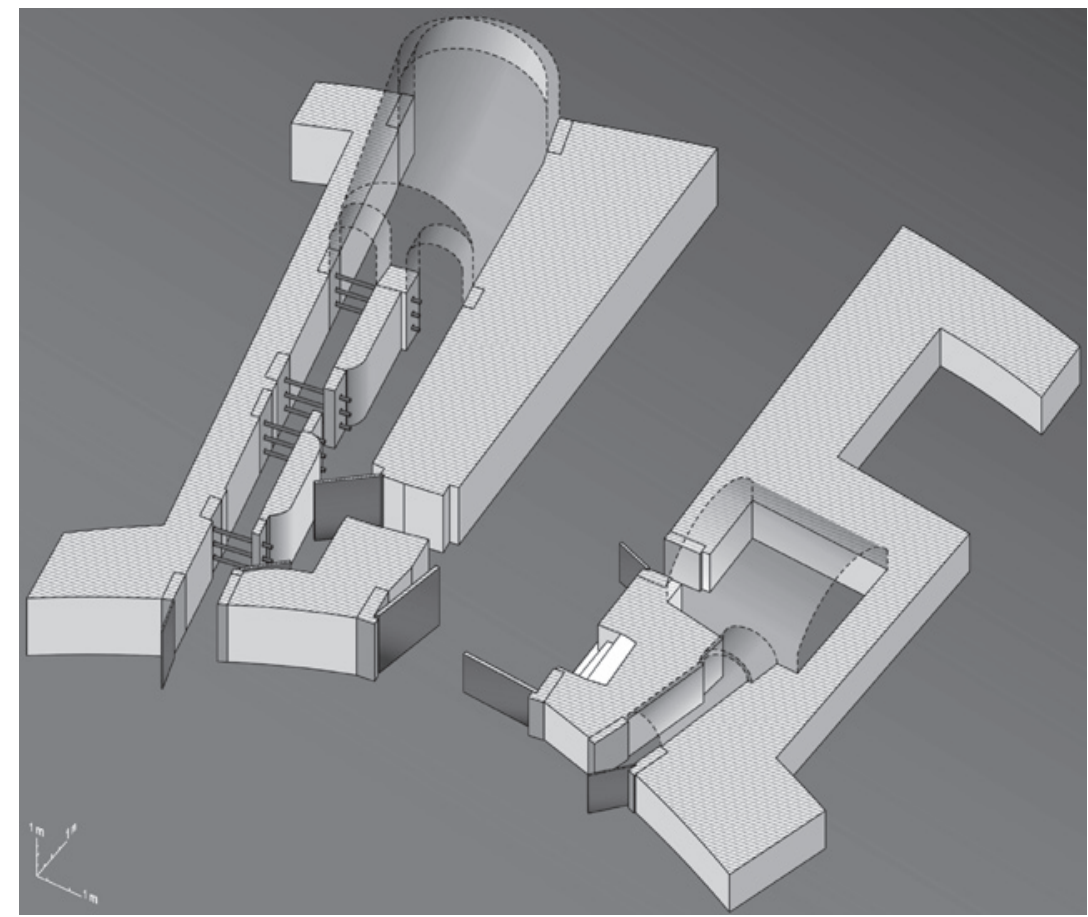

Abb. 7 - Amphitheater von Cividate Camuno, isometrische Ansicht des nördlichen Arenazugangs mit schmalem Tiergang, wohl zum Transport von Stieren, auf der westlichen Seite. Der Korridor konnte mittels horizontal eingeschobener Rundhölzer in einzelne Kompartimente unterteilt werden.

porta postica für das Arenapersonal kombiniert, finden sich in gutem Erhaltungszustand in den Amphitheatern von Lepcis Magna und Maktar (Abb. 6) ${ }^{22}$. Bei beiden Beispielen war die Tierpforte mit einem hinter der Schiebetüre liegenden engen Käfig versehen, der mit einem Arenaumgang oder einem Zubringergang in Verbindung stand. So war es möglich, auch während einer laufenden Vorstellung den Käfig mit neuen Tieren zu versorgen ${ }^{23}$.

22. Ibid., S. 215 ff. mit Abb. 216-223; dort auch weitere Beispiele und weiterführende Literatur.

23. Beim Beispiel von Maktar wurde der Käfig zum dahinterliegenden Gang hin lediglich mit zwei vertikal verschiebbaren Balken verschlossen, während bei demjenigen von Lepcis Magna eine weitere Schiebetür existierte. Auch die Bedienung der Schiebetüren wurde auf unterschiedliche Art gelöst; in Lepcis Magna erfolgte 
Eine andere spezifische Einrichtung zum Transport von Tieren in die arena ist aus den Amphitheatern von Carnuntum und Cividate Camuno bekannt. Hier existierte jeweils parallel zu einem der beiden ArenaHauptzugänge ein ca. $80 \mathrm{~cm}$ breiter Korridor, der mittels horizontal verschiebbarer Holzstangen in einzelne, 2-2,50 m lange Abteile abtrennbar war und über eine porta postica auf den Kampfplatz führte (Abb. 7) ${ }^{24}$. So entstand ein unter den Sitzstufen liegender Gang mit einzelnen, hintereinandergestaffelten Boxen, in denen die Tiere, in der Regel vermutlich Stiere, Wildesel und dergleichen, für ihren Auftritt bereitgestellt werden konnten.

\section{Soziale Funktion}

Da die Sitzplatzwahl nicht frei, sondern spätestens seit Augustus streng geregelt war, besassen die Theaterbauten eine wichtige Funktion als Spiegel der gesellschaftlichen Hierarchie. Jede soziale Gruppe besass im Theater oder Amphitheater ihre eigene Sitzzone, wobei die Nähe zur orchestra respektive zur arena für alle sichtbar Aufschluss über den gesellschaftlichen Rang der entsprechenden Gruppe lieferte ${ }^{25}$. Wie die Akten des Priesterkollegiums der Arvales fratres aus Rom für das Kolosseum zeigen, konnte jede Gruppe innerhalb des Theaters auf mehrere voneinander unabhängige Sitzplatzzonen Anspruch erheben. So besassen die Arvalen nebst einer Anzahl Plätze für sich selbst im podiumsnahen Teil des ersten Rangs (maenianum primum) auch noch zusätzliche im obersten Rang (maenianum summum) sowie auf der Holztribüne des obersten Rangs (maenianum summum in ligneis) ${ }^{26}$.

Gleichzeitig bildeten die Bauten auch einen hervorragenden Hintergrund für die Selbstdarstellung von Politikern und Euergeten, die

sie vom darübergelegenen Podiumumgang aus, in Maktar war ein Arenasklave zum Hochziehen des Schiebers direkt über dem Käfig postiert (Abb. 6).

24. Th. Hufschmid, Amphitheatrum in Provincia et Italia, S. 212 ff. mit Abb. 206213; V. Mariotti, „L'anfiteatro di Cividate Camuno “, S. $101 \mathrm{ff.}$

25. J. Kolendo, „La répartition des places aux spectacles et la stratification sociale dans l'Empire romain “, S. 301 ff.; P. Gros, „Théâtre et culte impérial en Gaule Narbonnaise et dans la péninsule ibérique “, S. 383; F. Sear, Roman theatres, S. $3 \mathrm{ff}$. 26. J. Scheid, Commentarii fratrum Arvalium qui supersunt, S. $126 \mathrm{f}$. 
ihren gesellschaftlichen Status mittels der Finanzierung von Spielen ${ }^{27}$ oder der Stiftung von Theaterbauten ${ }^{28}$, respektive Teilen davon ${ }^{29}$, demonstrieren konnten. Wie das Beispiel des flavischen Amphitheaters von Pozzuoli zeigt, scheinen zudem auch Kollegien und Korporationen zuweilen zur Finanzierung von Theaterbauten beigetragen zu haben; zumindest legt die Einrichtung der Versammlungslokale von bestimmten collegia in den Arkadensubstruktionen dieses Amphitheaters eine solche Vermutung nahe ${ }^{30}$.

\section{Politische Funktion}

Wie eingangs bereits erwähnt, kam den Theaterbauten eine erhebliche politische Bedeutung $\mathrm{zu}$, die sich in verschiedenen Bereichen manifestiert. Der politische Aspekt der Spiele wird zwar durchaus immer wieder erwähnt, unter dem von Iuvenal überlieferten Schlagwort von panem et circenses aber allzu oft als simple Massenunterhaltung dargestellt ${ }^{31}$, welche speziell in der Kaiserzeit dazu bestimmt gewesen sei, die Bevölkerung von der Politik abzulenken. Die Spiele seien demzufolge ein Kompensationselement für seitens der Herrscher unerwünschte politische Agitation und Meinungsäusserung gewesen ${ }^{32}$. Genau das Gegenteil

27. So zum Beispiel im Amphitheater von Arles (AE 1965, 270): C(aius) Iunius Priscus...[du] orum dierum [operas sca] en[i]cas, [uenati] onem edid[it ...].

28. Vgl. die Dedikationsinschrift des Amphitheaters von Lyon ( $A E$ 1959, 78 und 81; 1961, 62 und 328): C(aius) Iul(ius) C(aii) f(ilius) Rufus, sacerdos Rom(ae) et Aug(usti), [---] filii f(---) et nepos ex ciuitate Santon (um) d(e) s(ua) p(ecunia) fecerunt.

29. Vgl. dazu eine Inschrift aus dem Amphitheater von Virunum: ...C(aius) Cassius Honoratus...podium amp(h)itheatri opere tectorio cum pictura muneris sui exornauit... Vgl. H. Dolenz, „Die Inschriften aus dem Amphitheater von Virunum “, S. $290 \mathrm{f}$.

30. J.-C. Golvin, L'amphithéâtre romain, S. 181 ; D. Steuernagel, „Corporate identity", S. 155.

3I. Iuvenal, Satiren 10.81.

32. „Kein Zweifel, Juvenal hat hier zwei Dinge beschrieben, auf die sich die Herrschaft der Cäsaren in hohem Masse gestützt hat; einmal die kostenlose Getreideverteilung... zum anderen die aufwendigen Massenunterhaltungen, die der Zerstreuung der Menschen dienten - und der Ablenkung von der Politik“, vgl. K.-W. Weeber, Panem et Circenses, S. 2. Dieser unbedarften Auslegung des Textes ist entgegenzuhalten, dass es Juvenal als einem der bissigsten Moralisten der römischen Kaiserzeit nicht um ein objektives Abbild der bestehenden Zustände ging, sondern um die verklärende Darstellung einer vermeintlich tugendreicheren und 
ist jedoch der Fall! Die Popularität der Spiele und das breite Interesse an den Veranstaltungen der Theaterbühne, der arena und der Rennbahn führten dazu, dass diese sich zunehmend zu einem Aushängeschild römischer Wertvorstellungen entwickelten. Speziell am Beispiel des Amphitheaters lässt sich hervorragend aufzeigen, wie die Symbolik und Bildsprache der Veranstaltungen zunehmend an Bedeutung gewann, so dass sich die Semantik der arena (wie auch diejenigen des Circus und des Bühnentheaters) letztlich zu einem wichtigen Propagandainstrument imperialer Machtdurchsetzung entwickelte.

\subsection{Theaterbauten als Versammlungsort}

Mit ihrer speziellen architektonischen Struktur, welche es ermöglichte, auch eine grössere Menschenmenge so in sich aufzunehmen, dass diese das Geschehen an einem eng umrissenen Punkt (Bühne, orchestra, arena) innerhalb des Gebäudes mitverfolgen konnte, waren die antiken Theaterbauten ideale Versammlungsorte ${ }^{33}$. Die antiken Quellen zeigen immer wieder, dass die Theater als multifunktionale Bauwerke zu verstehen sind, in denen vom unterhaltsamen Schwank bis zur staatsgefährdenden politischen Manifestation vieles stattfinden konnte. Die bei Apuleius wiedergegebene „Gerichtsszene “, in welcher der Protagonist Lucius zur Belustigung des Volkes als vermeintlicher Mörder vorgeführt wird ${ }^{34}$, zeigt dies ebenso, wie das bis in die späte Republik gültige Gesetz, wonach, wohl aus Angst vor politischer Agitation, in Rom bis ins Jahr 55 v. Chr. die Errichtung eines permanenten, aus Stein gebauten Theaters verboten war $^{35}$.

Exemplarisch zeigt sich die Bedeutung des Versammlungsaspekts schliesslich beim „amphithéâtre des Trois Gaules “von Lyon, das in Zusammenhang mit dem Provinziallandtag der gallischen Stämme auf dem Gebiet der 12 v. Chr. von Drusus errichteten ara Romae et Augusti gebaut wurde ${ }^{36}$. Wie die jüngste Forschung zeigt, scheint dieser Aspekt

besseren Vergangenheit. Vgl. dazu auch A. Hönle, A. Henze, Römische Amphitheater und Stadien, S. 11.

33. Vgl. dazu auch W. van Andringa, La religion en Gaule romaine, S. $115 \mathrm{mit}$ Anm. 118.

34. Apuleius, Metamorphosen 3.2.6ff.

35. J.-C. Golvin, L'amphithéatre romain, S. $22 \mathrm{f}$.

36. D. Fishwick, The imperial cult in the Latin West, S. $580 \mathrm{ff}$. 
auch über Lyon hinaus für eine Vielzahl der gallo-römischen Theater und Amphitheater von Bedeutung zu sein ${ }^{37}$.

3.2. Die Architektur der Theaterbauten als Symbol des imperialen Machtanspruchs

Seit jeher dienten Bauwerke nicht nur als Zweckbauten sondern auch als sichtbares Zeugnis für den sozialen Stand und die politische Macht ihres Besitzers respektive Auftraggebers (Abb. 8). In diesem Sinne dürfte bereits die blosse Existenz eines Theaters oder Amphitheaters innerhalb einer Stadt oder Kolonie ein deutliches Zeichen für deren politischen Status dargestellt haben. In vielen Fällen standen die Bauwerke zudem mit Sakralkomplexen in Verbindung oder waren gar integraler Bestandteil von dem Kaiserkult gewidmeten Heiligtümern und dienten dadurch als wichtiges Instrument für die Inszenierung der kaiserlichen Herrschaft und des universalen Machtanspruchs des römischen Volkes.

\subsection{Theaterbauten als Ort der politischen Interaktion}

Da das Publikum im Theater und im Amphitheater keine passive Rolle übernahm, sondern aktiv in den Ablauf der Spiele eingriff, sei es etwa beim Entscheid über Leben (missio) oder Tod (iugulatio) des unterlegenen Gladiators bei den munera, sei es bei den revocationes im Bühnentheater ${ }^{38}$, entstand eine Art politischer Diskurs zwischen

37. Th. Hufschmid, Amphitheatrum in Provincia et Italia, S. $183 \mathrm{f}$; ; R. Etienne, „Un complexe monumental du culte impérial à Avenches “, S. $16 \mathrm{ff}$.

38. Bei den revocationes handelt es sich um eine Form der Interaktion zwischen Publikum und politischen Amtsträgern im Theater. Dabei wurden bestimmte Passagen eines Stücks auf tagespolitische Aktualitäten bezogen und der deklamierende Schauspieler durch lautes Zurufen aufgefordert, die entsprechende Stelle ein- oder sogar mehrmals zu wiederholen, um damit die Zustimmung oder das Missfallen zu bestimmten politischen Ereignissen kundzutun. Die Spielgeber ihrerseits konnten durch die Auswahl der Stücke und die Instruktion der Schauspieler in Bezug auf die Deklamationsweise bestimmter Passagen und die dabei verwendete Gestik Einfluss auf das Publikum nehmen oder diesem eine bestimmte politische Haltung zum Ausdruck bringen. Auch wurden zuweilen bezahlte Claqueure angestellt, welche im Verlauf der Aufführung revocationes in Gang setzten, um so die politische Haltung des Spielgebers oder eines einflussreichen Bürgers als „Volksmeinung " zu inszenieren. Vgl. dazu auch E. Flaig, Ritualisierte Politik, S. $239 \mathrm{ff}$. 


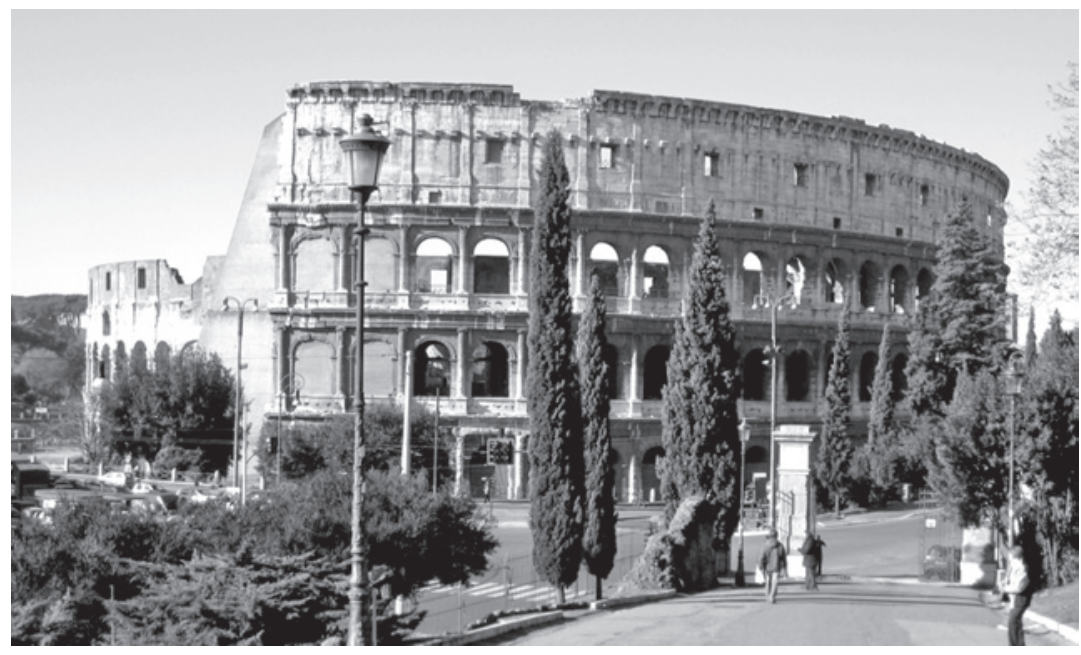

Abb. 8 - Sinnbild imperialer Macht, das Kolosseum mit seiner vierstöckigen Fassade vom Colle Oppio her gesehen.

dem einfachen Volk und den einflussreichen Bürgern, respektive dem Kaiser oder dessen Beamten und seinen Untertanen (Abb. 9). Im Falle der revocationes im Theater diente die Interaktion einer Visualisierung der (zuweilen auch künstlich erzeugten oder mit bestimmten Mitteln provozierten) „Stimmung im Volk“ (favor populi) und dem Einfordern bestimmter Versprechungen von den politischen Amtsträgern oder gar dem Kaiser selbst. Zuweilen kam es auch vor, dass ein bei einer Mehrheit der einfachen Bevölkerung unbeliebter Politiker beim Betreten des Theaters vom Publikum durch Drohungen und Ausbuhen oder durch verlangte revocationes in höchstem Grad kompromittiert wurde ${ }^{39}$.

Eine ein wenig andere Interaktion zwischen Publikum und Spielgeber erfolgte bei den Gladiatorenkämpfen im Amphitheater. Beim Entscheid über die missio oder die iugulatio des im Kampf unterlegenen Gladiators ging es zwar ebenfalls um die Äusserung einer kollektiven Haltung, diesmal aber nicht um eine, welche die politische Befindlichkeit der Volksmassen wiedergab. Vielmehr war der Entscheid um die missio, zweifellos der Höhepunkt eines jeden Gladiatorenkampfs, ein hochgradig emotionaler Moment, der dazu diente, die heterogene Masse

39. Dies musste beispielsweise Publius Clodius bei den ludi Apollinares des Jahres 57 v. Chr. erfahren. Vgl. R. C. Beacham, The Roman theatre and its audience, S. 158. 


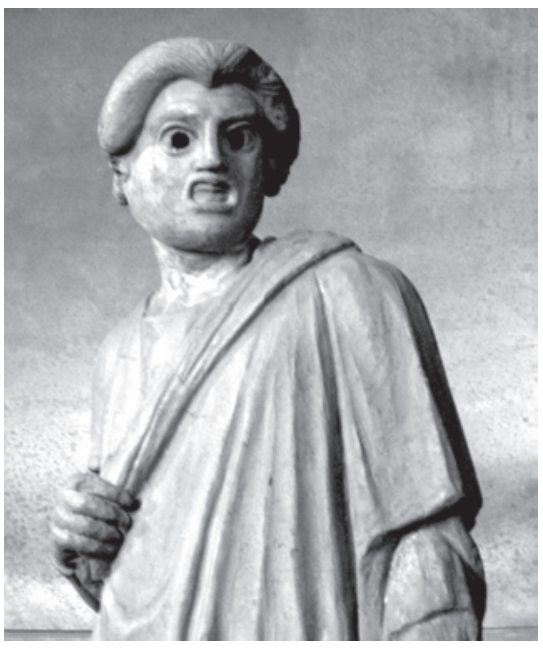

Abb. 9 - Terrakottastatue eines römischen Schauspielers mit Maske, aus Pompeji.

der Zuschauer zu einer Einheit zu verschmelzen, welche im Stand war, die sich in den Spielen der arena spiegelnden Wertvorstellungen der römischen Zivilisation zu erkennen und zu beurteilen ${ }^{40}$. Ein Entscheid darüber, ob der unterlegene Gladiator gut genug gekämpft hatte, um sich das Weiterleben zu verdienen, war nur möglich, wenn diesbezüglich Einigkeit unter den Zuschauern herrschte. Diese unanimitas sorgte dafür, dass die einzelnen Individuen sich als Teil einer von klaren Wertvorstellungen geprägten römischen Welt fühlten, welche für jedermann sichtbar vom Kaiser, seinen Beamten und den führenden Politikern in der arena der Amphitheater visualisiert wurde ${ }^{41}$.

\subsection{Die Veranstaltungen in den Theaterbauten als Kodex einer "politisch-kulturellen Identität"}

Die durch die Spiele symbolisierte politische Ordnung, in der unterlegene Völker dominiert, die Natur beherrscht und Verbrecher bestraft wurden, gehörte zu den grundlegenden Wertvorstellungen der römischen Gesellschaft, die es der Masse der Bevölkerung auf möglichst eingängige, visuell erfassbare Art zu vermitteln galt ${ }^{42}$. Wenn in den arenae der Amphitheater die Gladiatoren im tödlichen Kampf gegeneinander antraten, taten sie dies stets in klar definierten Gattungen (armaturae), die zumeist ethnisch inspiriert waren. Gladiatorentypen wie der Thraker

40. E. Flaig, Ritualisierte Politik, S. $248 \mathrm{ff}$.

4I. Th. Hufschmid, Amphitheatrum in Provincia et Italia, S. 266 ff. - Zur Bedeutung der unanimitas für die römischen Spiele, vgl. M. Clavel-Lévêque, „L'espace des jeux dans le monde romain “, S. $2487 \mathrm{ff}$.

42. Zur politischen Semantik der römischen Arenaspiele, vgl. E. Flaig, „Gladiatorial games ", S. $84 \mathrm{ff}$. 
(thraex), der den keltischen Streitwagen fahrende essedarius oder der durch seinen Namen mit Griechenland verknüpfte hoplomachus entsprachen Angehörigen unterworfener Gebiete, die in der arena unter der Aufsicht und zur Unterhaltung des römischen Volkes gegeneinander kämpften ${ }^{43}$. Sie taten dies in einer genau umrissenen Zone innerhalb des Amphitheaters, wo der Kampfplatz mittels der Podiumsmauer klar vom Zuschauerbereich getrennt war. Das römische Volk war als Publikum somit nicht Teil des Geschehens, dominierte aber über die Handlung in der arena und urteilte regelmässig über das Schicksal der Akteure. Semantisch betrachtet wiederholte sich so die Vernichtung der Feinde Roms tagtäglich in der arena und das römische Imperium mit seinem Kaiser an der Spitze zelebrierte unablässig seinen Sieg über die unterworfenen Völker. Dieser Machtanspruch beschränkte sich aber nicht nur auf unterlegene Völker, sondern erstreckte sich auch auf die Tier- und Pflanzenwelt. Durch die Inszenierung von grossartig angelegten Jagdveranstaltungen, bei denen in der arena künstliche Landschaften mit Bäumen und Felsen (paradeisos) aufgebaut wurden, kam zum Ausdruck, dass das römische Volk und im speziellen sein Kaiser auch über die Natur gebot und diese gemäss seinem Willen gestalten und verändern konnte ${ }^{44}$. Auf spezielle Kunststücke dressierte Tiere demonstrierten die Überlegenheit der römischen Kultur über die wilde Natur und abgerichtete Gazellen und Elefanten knieten vor dem Kaiser, dem Herrscher über den Erdkreis, nieder. Die Inszenierung der imperialen Macht reichte aber noch weiter. Durch die öffentliche Bestrafung von Verbrechern in der arena war für alle sichtbar, dass die Feinde des Staates und der römischen Gesellschaft für ihre Taten zur Rechenschaft gezogen wurden. Geschah dies gar in Form von Inszenierungen bekannter Sagen, bei denen der Protagonist unweigerlich zu Tode kam und zumeist von wilden Tieren zerfleischt wurde, so war dies umso mehr ein Zeichen dafür, dass der princeps und seine Beamten gar im Stande waren, die Mythen lebendig werden zu lassen ${ }^{45}$. Die Spiele kreierten somit unablässig Bilder und Symbole, welche den römischen Herrschaftsanspruch

43. Th. Hufschmid, Amphitheatrum in Provincia et Italia, S. 269; M. ClavelLévêque, L'empire en jeux, S. 64.

44. Th. Hufschmid, Amphitheatrum in Provincia et Italia, S. $246 \mathrm{ff} ., 265$ und 270.

45. Th. Hufschmid, Amphitheatrum in Provincia et Italia, S. 270 f.; K. M. Coleman, „Fatal charades “, S. 73. 
unter der Führung des Kaisers zelebrierten und legitimierten. Durch die so geschaffene Bildsprache und das Zusammengehörigkeitsgefühl der unanimitas fühlten sich die Zuschauer dem orbis romanus zugehörig und hatten Teil an diesem durch die pax romana ermöglichten „Triumph der römischen Zivilisation " 46 .

Mit dieser politischen Vereinnahmung der Spiele erhielten die Amphitheater im Verlauf der Kaiserzeit aber noch einen zusätzlichen Aspekt: Sie entwickelten sich zunehmend zu in Stein gebauten Symbolen des Sieges über sämtliche die römische Ordnung bedrohende äussere Einflüsse. Und in der Tat finden sich bei diversen Amphitheatern bauliche Konzepte, darunter etwa monumentale triumphbogenartige Eingangsbereiche, welche an eine eigentliche "Siegestheologie“ denken lassen ${ }^{47}$. In beeindruckender Art und Weise manifestierte sich diese gesteigerte Siegessymbolik auch in den 1816 durch Frost zerstörten Malereien an der Podiumsmauer des Amphitheaters von Pompeji ${ }^{48}$. Dieser von qualitätvollen Gladiatoren- und Tierkampfdarstellungen geprägte Bildzyklus war mit einer Reihe von sich wiederholenden Zwischenmotiven versehen, welche den in der arena vorherrschenden Siegesaspekt deutlich zum Ausdruck brachten. Victorien, welche Siegeskränze (coronae) und Palmwedel (palmae) in den Händen hielten, auf tordierten Kandelabern stehende imagines clipeatae sowie Büstenhermen mit angelehntem Schild sind denn auch klare Siegessymbole, welche den Protagonisten der arena die Zielsetzung ihres Kampfes vor Augen führten. Gleichzeitig besass aber jedes dieser Siegeszeichen gleichsam eine Kehrseite, welche zum Ausdruck brachte, dass die arena für den schlecht Kämpfenden auch Niederlage und Tod bedeutete. Die Victorien erinnern in der Art ihrer Darstellung deutlich an Nemesis, die launenhafte Schicksalsgöttin der arena, die auch Unheil und Tod bringen konnte; ebenso tauchen die imagines clipeatae nicht nur in der Triumphalkunst auf, sondern besitzen auch eine zentrale Bedeutung im Totenkult und letztlich schwingt bei den Büstenhermen der Aspekt des Hermes Psychopompos, des Begleiters der Verstorbenen

46. Th. Hufschmid, Amphitheatrum in Provincia et Italia, S. $271 \mathrm{f} . ;$ M. ClavelLévêque, L'empire en jeux, S. 70.

47. Ph. Bridel, L'amphithéâtre d'Avenches, S. 216 ff.; M. Clavel-Lévêque, „L'espace des jeux dans le monde romain ", S. $2474 \mathrm{ff}$.

48. Th. Hufschmid, Amphitheatrum in Provincia et Italia, S. $259 \mathrm{ff}$. 
in die Unterwelt, mit. Diese Ambivalenz in den auf die Podiumsmauer gemalten Darstellungen macht das Gesetz der arena unmissverständlich klar: Im Vordergrund steht der Sieg im Kampf, dieser ist aber nur durch militärische virtus und die Überwindung des im Hintergrund lauernden Todes zu erringen. Wer die arena als Akteur betritt, verlässt sie entweder lebend durch die porta sanavivaria oder tot durch die porta libitinensis. Die Nomenklatur der Tore wird somit zum politisch-ideologischen Programm ${ }^{49}$.

\section{Religiöse Funktion}

Die Verbindung von Kult und Theaterbauten besitzt eine lange Tradition und ist bereits für das klassische Athen von erheblicher Bedeutung. $\mathrm{Zu}$ Ehren von Dionysos fanden dort spätestens ab der 2. Hälfte des 6. Jh. v. Chr. regelmässig Festspiele in dem am Fuss der Akropolis errichteten Dionysos-Theater statt; Spiele, die nicht als einfache Unterhaltung, sondern zusammen mit der dazu gehörenden Prozession als wesentlicher Bestandteil der Kulthandlungen zu verstehen sind ${ }^{50}$. Diese Verbindung ist in der römischen Kultur keineswegs anders, die Vielzahl an ludi, die uns überliefert sind, zeigt deutlich, dass säkulare Spiele im modernen Sinn nicht existierten ${ }^{51}$. Die Veranstaltungen fanden zumeist zu Ehren bestimmter Gottheiten oder der Manen Verstorbener statt und die Bauten standen nicht selten in irgendeiner Form mit Heiligtümern oder Sakralbezirken in Zusammenhang. Deutlich wird dies spätestens mit der Errichtung des Pompejus-Theaters in Rom im Jahre 55 v. Chr., das mit seinem bekrönenden, der Venus Victrix geweihten Tempel die Verbindung zwischen Göttern und Spielen augenfällig macht ${ }^{52}$. Das Theater des Pompejus blieb dabei kein Einzelbeispiel und fand in den folgenden drei Jahrhunderten in Italien, Spanien und Frankreich diverse Nachahmungen. Daneben entstanden, wohl nicht zuletzt aus der Tradition der in Latium beheimateten Heiligtümer von Tivoli, Gabii

49. Ibid., S. 266.

50. H.-D. Blume, Einführung in das antike Theaterwesen, S. $14 \mathrm{ff}$.

5I. J. A. Hanson, Roman theater-temples, S. $10 \mathrm{ff}$.

52. Ibid., S. $43 \mathrm{ff}$. 


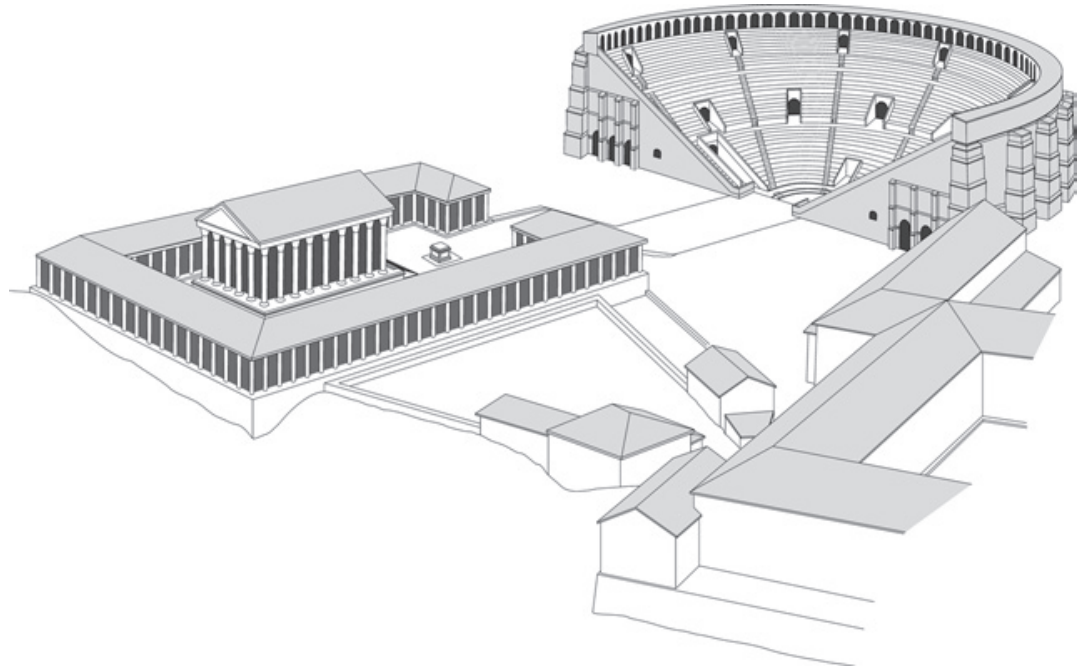

Abb. 10 - Augusta Raurica, Heiligtum von Augst-Schönbühl mit Podiumtempel, umgebender Doppelporticus und im Osten angegliedertem Theater vom gallorömischen Typ (mit offener Bühnenwand). Zustand um 200 n. Chr., ohne Massstab.

oder Praeneste heraus ${ }^{53}$, weitere Verbindungen zwischen Tempel und Theaterbauten. Das bekannteste Phänomen bilden dabei axiale Bezüge zwischen den beiden Bauwerken, wie wir sie beispielsweise aus Ostia, Lepcis Magna oder Champlieu kennen ${ }^{54}$, aber auch aus Mandeure, Aventicum $^{55}$ und Augusta Raurica ${ }^{56}$, um näher gelegene Beispiele zu nennen (Abb. 10). Die enge Verbindung zwischen Heiligtum und Theaterbau beschränkt sich dabei keineswegs nur auf die Bühnentheater, sondern findet sich speziell in der Kaiserzeit auch bei den Amphitheatern und den Circi, wie die Beispiele von Ankara, Tarragona, Lyon, Amiens oder Augst-Neun Türme bestens illustrieren ${ }^{57}$.

53. Ibid., S. 29 ff.; R. Etienne, „Un complexe monumental du culte impérial à Avenches ", S. $19 \mathrm{f}$.

54. R. Etienne, „Un complexe monumental du culte impérial à Avenches“, S. 21; Th. Hufschmid, Amphitheatrum in Provincia et Italia, S. $177 \mathrm{ff}$.

55. R. Etienne, „Un complexe monumental du culte impérial à Avenches “, S. $18 \mathrm{f}$.

56. Th. Hufschmid, I. Horisberger, „, Ipsius autem theatri conformatio sic est facienda... ", S. $190 \mathrm{ff}$.

57. R. Etienne, „Un complexe monumental du culte impérial à Avenches “, S. 13 und 18; Th. Hufschmid, Amphitheatrum in Provincia et Italia, S. 177 ff.; Th. Hufschmid, I. Horisberger, „, Ipsius autem theatri conformatio sic est facienda... " “, S. $190 \mathrm{ff}$. 
Aber auch die Bauwerke selbst oder zumindest Teile davon scheinen in der Antike als Ort göttlicher Präsenz manifest gewesen zu sein, so dass Tertullians Aussage, wonach das Amphitheater omnium daemonum templum sei, wohl doch über den Aspekt der simplen christlichen Polemik hinausgeht ${ }^{58}$. Der grundsätzliche Charakter des Amphitheaters als Ort tödlicher Spiele und die mit ihm verbundene Nomenklatur legen nahe, dass die arena mit grosser Wahrscheinlichkeit als „Ort zwischen Diesseits und Jenseits" zu verstehen ist ${ }^{59}$. Befand man sich einmal in der arena, so wurde man sich dieser Situation bewusst, indem lediglich zwei grosse Tore wieder aus dem Kampfplatz hinaus führten, nämlich das "Tor des Leben “, die porta sanavivaria, und das "Tor des Todes“, die porta libitinensis ${ }^{60}$. Der Stellenwert dieser Tore als Übergang zwischen Bereichen unterschiedlicher Bedeutung wird auch durch die bereits erwähnten Malereien an der Podiumsmauer des Amphitheaters von Pompeji unterstrichen. Dort wurden die beiden Haupttore arenaseitig jeweils von zwei antithetisch angebrachten Torhermen bewacht, die mit ihren Attributen, dem pedum und der situla, deutlich religiöse Bezüge aufweisen ${ }^{61}$. Während das pedum eine Verbindung zur Sphäre des Dionysos (wohl in seiner chthonischen Erscheinungsform) schafft ${ }^{62}$, scheint die situla auf einen Opferkontext zu verweisen, der möglicherweise als Reinigungsritual beim Verlassen des Kampfplatzes zu interpretieren ist. Überhaupt scheint die arena der Amphitheater als Ort der Präsenz chthonischer Gottheiten und Dämonen betrachtet worden zu sein. Dies zeigt sich deutlich in den Funden zahlreicher Fluchtäfelchen aus Blei (tabellae defixionum), die beispielsweise in den Amphitheatern von Karthago, Trier, London oder Caerleon zum Vorschein gekommen sind, und sich an eine ganzen Palette von chthonischen Gottheiten,

58. Tertullian, De spectaculis 12.7; M. Clavel-Lévêque, L'empire en jeux, S. 66.

59. Th. Hufschmid, Amphitheatrum in Provincia et Italia, S. 272 ff.; K. M. Coleman, „Fatal charades “, S. 67.

6o. Zur Bedeutung dieser beiden Tore, vgl. Th. Hufschmid, Amphitheatrum in Provincia et Italia, S. 42 f.

6I. Ibid., S. 263.

62. Dionysos/Bacchus wurde in Rom für gewöhnlich mit Liber Pater gleichgesetzt (J. Scheid, „Bacchus “), dessen Verbindung zur arena literarisch und epigraphisch fassbar ist. Vgl. Tertullian, Ad nationes 1.10.47; M. Le Glay, „Les amphithéâtres “, S. 219. 
darunter auch Nemesis, Diana und Mars sowie heute nicht genauer bekannten Dämonen, richteten ${ }^{63}$.

\section{Fazit}

Zusammenfassend lässt sich also festhalten, dass die römischen Theaterbauten im Allgemeinen und die Amphitheater mit ihrer vielseitig einsetzbaren arena im Speziellen als hochgradig multifunktionale Bauwerke zu betrachten sind ${ }^{64}$. In diesem Zusammenhang bezieht sich die Funktionalität einerseits auf rein technische, zuweilen höchst komplexe Installationen, wie sie etwa die Lift- und Hebeeinrichtungen in den Amphitheatern darstellen, andererseits aber auch auf die generelle Disposition der Erschliessungssysteme mit ihren Gängen und Räumen, wie sie bei sämtlichen Theaterbauten anzutreffen ist. Diese aufwändigen technischen Einrichtungen waren letztlich aber nur Mittel zum Zweck, damit die Bauwerke und die in ihnen abgehaltenen Veranstaltungen viel weiter reichende soziale, politische und religiöse Funktionen erfüllen konnten ${ }^{65}$. Die durch die Architektur der Bauwerke und die Ideologie der Spiele eröffneten vielschichtigen Möglichkeiten, machten die Theaterbauten und ihre Veranstaltungen zu idealen Kristallisationspunkten für die Vermittlung von romanitas in ihrer ganzen Breite. Letztlich entstand eine eigene Semantik der ludi, welche durch die Hierarchie der Sitzplätze und die auf Euergetismus beruhende Selbstdarstellung der Eliten und Korporationen nicht nur das soziale Gefüge der römischen Gesellschaft vor Augen führte, sondern durch die stark politisch und religiös kontaminierten Inhalte der Veranstaltungen auch die römische Weltordnung, die imperiale Machtideologie und das auf der pax deorum beruhende Einvernehmen mit den Göttern propagierte (Abb. 11) ${ }^{66}$. Wenn aber die Spiele einen politischen Akt und einen

63. Th. Hufschmid, Amphitheatrum in Provincia et Italia, S. $272 \mathrm{f}$; N. Bateman, "What's the point of London's amphitheatre?", S. $157 \mathrm{ff}$.

64. Th. Hufschmid, Amphitheatrum in Provincia et Italia, S. $278 \mathrm{ff}$.

65. Ibid., S. 266 ff.; M. Le Glay, „Les amphithéâtres“, S. 222 f.; N. Bateman, „What's the point of London's amphitheatre? “, S. $160 \mathrm{ff}$.

66. M. Le Glay, „Les amphithéâtres “, S. 222 f.; E. Flaig, „Gladiatorial games “, S. 84 ff.; M. Clavel-Lévêque, L'empire en jeux, S. 175; P. Gros, „Théâtre et culte impérial en Gaule Narbonnaise“, S. 389; J. A. Hanson, Roman theater-temples, S. 91. 
attraktive Spiele, populäre Veranstaltungen

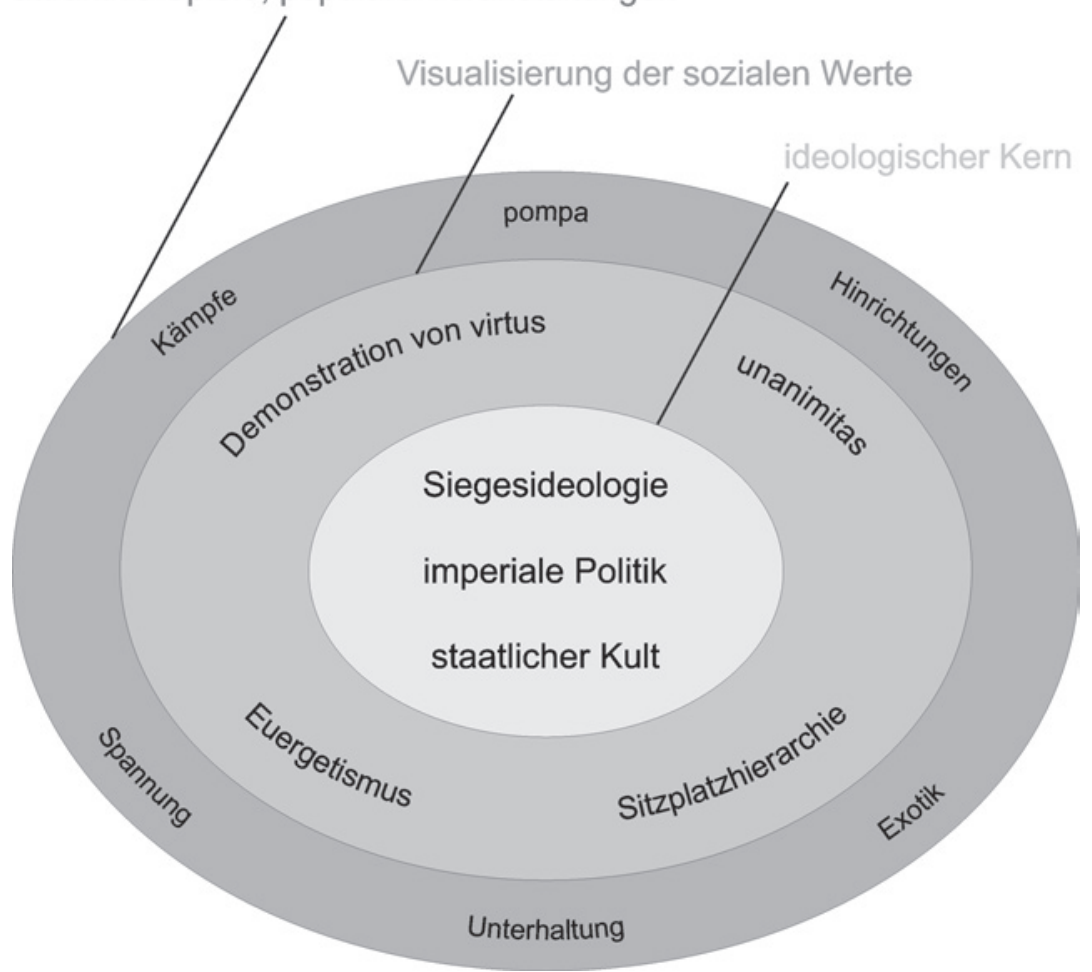

Abb. 11 - Schema der verschiedenen Funktionsebenen von Veranstaltungen im Amphitheater.

Dienst an den Göttern darstellten, so sind die Bauten, in denen sie stattfanden, als Teil der oft an sie angrenzenden Heiligtümer und somit in gewissem Sinne als sakrale Bauten zu betrachten ${ }^{67}$.

Thomas Hufschmid Augusta Raurica, Theaterprojekt

67. Th. Hufschmid, Amphitheatrum in Provincia et Italia, S. 271 f.; N. Bateman, „What's the point of London's amphitheatre? “, S. 160. 


\section{BIBLIOGRAPHIE}

\section{Quellen}

Apuleius Madaurensis, Lucius, Metamorphosen - Der goldene Esel, lateinisch und deutsch, herausgegeben und übersetzt von E. Brandt und W. Ehlers, mit einer Einführung von N. Holzberg, Düsseldorf/Zürich, Artemis und Winkler, 19985.

Calpurnius Siculus, Titus, Eclogae - Bucoliques. Pseudo-Calpurnius, Eloge de Pison, texte établi et traduit par J. Amat, Paris, Les Belles Lettres, 1991.

Isidorus Hispalensis, Etymologiae - The etymologies of Isidore of Seville, translated, with introduction and notes, by Stephen A. Barney, New York, Cambridge University Press, 2006.

Iuvenal, Decimus Iunius, Satiren - Saturae, lateinisch-deutsch, herausgegeben, übersetzt und mit Anmerkungen versehen von J. Adamietz, München/Zürich, Artemis und Winkler, 1993.

Seneca, Lucius Annaeus, Epistulae morales ad Lucilium - Briefe an Lucilius, lateinisch-deutsch, herausgegeben und übersetzt von G. Finck, Düsseldorf, Artemis und Winkler, 2007.

Tertullian, Quintus Septimius Florens, Ad nationes, liber 1 - Le premier livre ad nationes de Tertullien, introduction, traduction et commentaire de A. Schneider, Rome, Institut suisse, 1968 (Bibliotheca Helvetica Romana 9).

—, De spectaculis - Les spectacles, introduction, texte critique, traduction et commentaire de M. Turcan, Paris, Les Editions du Cerf, 1986.

\section{Studien}

Andringa, William van, La religion en Gaule romaine. Piété et politique (I ${ }^{e r}$-III siècle apr. J.-C.), Paris, Errance, 2002. 
Bateman, Nick, „What's the point of London's amphitheatre? A clue from Diana", in Roman amphitheatres and spectacula: a 21stcentury perspective. Papers from an international conference held at Chester, 16th-18th February, 2007, ed. Tony Wilmott, Oxford, Archaeopress, 2009, S. 157-163.

Beacham, Richard C., The Roman theatre and its audience, London, Routledge, 1991.

Beste, Heinz-Jürgen, „I sotterranei del Colosseo: Impianto, trasformazioni e funzionamento ", in Sangue e Arena, ed. Adriano La Regina, Roma, Electa, 2001, S. 277-299.

Blume, Horst-Dieter, Einführung in das antike Theaterwesen, Darmstadt, Wissenschaftliche Buchgesellschaft, 19913.

Bridel, Philippe, L'amphithéâtre d'Avenches, Lausanne, Cahiers d'archéologie romande, 2004 (Cahiers d'archéologie romande 96, Aventicum XIII).

Cianco Rossetto, Paola, Pisani Sartorio, Giuseppina, Teatri greci e romani. Alle origini del linguaggio rappresentato, Roma, Seat, 1994-1996.

Clavel-LÉvêque, Monique, L'empire en jeux. Espace symbolique et pratique sociale dans le monde romain, Paris, Editions du Centre National de la Recherche Scientifique, 1984.

—, „Lespace des jeux dans le monde romain: hégémonie, symbolique et pratique social ", Aufstieg und Niedergang der römischen Welt, 2.16.3 (1986), S. 2405-2563.

Coleman, Kathleen M., „Fatal charades: Roman executions staged as mythological enactments ", Journal of Roman Studies, 80 (1990), S. 44-73.

Dolenz, Heimo, „Die Inschriften aus dem Amphitheater von Virunum ", in Virunum. Das römische Amphitheater. Die Grabungen 1998-2001, Hrsg. Renate Jernej, Christian Gugl, Klagenfurt/Celovec, Wieser Verlag, 2004, S. 269-322.

Etienne, Robert, „Un complexe monumental du culte impérial à Avenches ", Bulletin de l'Association Pro Aventico, 29 (1985), S. 5-26.

Fishwick, Duncan, The imperial cult in the Latin West. Studies in the ruler cult of the western provinces of the Roman Empire II, Leiden, E. J. Brill, 1991. 
Flaig, Egon, Ritualisierte Politik. Zeichen, Gesten und Herrschaft im Alten Rom, Göttingen, Vandenhoeck und Ruprecht, 2003.

—, "Gladiatorial games: ritual and political consensus “, in Roman by integration: dimensions of group identity in material culture and text, eds Roman Roth, Johannes Keller, Portsmouth, Journal of Roman Archaeology, 2007, S. 83-92.

Gabucci, Ada (ed.), Il Colosseo, Milano, Electa, 1999.

Golvin, Jean-Claude, L'amphithéâtre romain. Essai sur la théorisation de sa forme et de ses fonctions, Paris, de Boccard, 1988.

Gros, Pierre, „Théâtre et culte impérial en Gaule Narbonnaise et dans la péninsule ibérique ", in Stadtbild und Ideologie. Die Monumentalisierung hispanischer Städte zwischen Republik und Kaiserzeit, Hrsg. Walter Trillmich, Paul Zanker, München, Verlag der Bayerischen Akademie der Wissenschaften, 1990, S. 381-390.

Hanson, John A., Roman theater-temples, Princeton, Princeton University Press, 1959.

Hönle, Augusta, Henze, Anton, Römische Amphitheater und Stadien. Gladiatorenkämpfe und Zirkusspiele, Feldmeilen, Raggi-Verlag, 1981.

Hufschmid, Thomas, Amphitheatrum in Provincia et Italia. Architektur und Nutzung römischer Amphitheater von Augusta Raurica bis Puteoli, Augst, Augusta Raurica, 2009.

Hufschmid, Thomas, Horisberger, Ines, „, Ipsius autem theatri conformatio sic est facienda ...' 16 Jahre Forschung und Restaurierung im römischen Theater von Augst ", Jahresberichte aus Augst und Kaiseraugst, 29 (2008), S. 161-225.

Junkelmann, Marcus, Das Spiel mit dem Tod. So kämpften Roms Gladiatoren, Mainz, Philipp von Zabern, 2000.

Kolendo, Jerzy, „La répartition des places aux spectacles et la stratification sociale dans l'Empire romain. A propos des inscriptions sur les gradins des amphithéâtres et théâtres “, Ktema, 6 (1981), S. 301-315.

Le Glay, Marcel, „Les amphithéâtres: Loci religiosi?“, in Spectacula I. Gladiateurs et amphithéâtres. Actes du colloque tenu à Toulouse et à Lattes les 26, 27, 28 et 29 mai 1987, éds Claude Domergue, Christian Landes, Jean-Marie Pailler, Lattes, Imago, 1990, S. 217-225. 
Maiuri, Amedeo, Studi e ricerche sull'Anfiteatro Flavio Puteolano, Napoli, Gaetano Macchiaroli Editore, 1955.

Mariotti, Valeria, „L'anfiteatro di Cividate Camuno. Analisi architettonica e comparativa ", in Il teatro e l'anfiteatro di Cividate Camuno. Scavo, restauro e allestimento di un parco archeologico, ed. Valeria Mariotti, Firenze, All'insegna del Giglio, 2004, S. 95-112. ScheID, John, „Bacchus“, in Der Neue Pauly. Enzyklopädie der Antike, Hrsg. Hubert Cancik, Helmuth Schneider, Stuttgart/Weimar, J. B. Metzler, 1996 ff., S. 390-391.

- Commentarii fratrum Arvalium qui supersunt. Les copies épigraphiques des protocoles annuels de la confrérie arvale (21 av.-304 ap. J.-C.), Rome, Ecole Française de Rome, 1998.

SeAr, Frank, Roman theatres. An architectural study, Oxford, Oxford University Press, 2006.

Steuernagel, Dirk, „Corporate identity. Über Vereins-, Stadt- und Staatskulte im kaiserzeitlichen Puteoli “, Mitteilungen des Deutschen Archäologischen Instituts Rom, 106 (1999), S. 149-187.

Weeber, Karl-Wilhelm, Panem et circenses. Massenunterhaltung als Politik im antiken Rom, Mainz, Philipp von Zabern, 1994.

Welch, Katherine E., The Roman amphitheatre. From it's origins to the Colosseum, Cambridge, Cambridge University Press, 2007.

\section{Abbildungsnachweis}

Abb. 1-11 :

Thomas Hufschmid. 
